\title{
Obtenção de Lipases Microbianas: Uma Breve Revisão
}

\section{Obtaining of Microbial Lipase: A Brief Review}

\author{
José Lucas de Almeida Antunes Ferraz \\ Universidade Estadual de Santa Cruz - UESC, Ilhéus, BA \\ lucasferraz_15@hotmail.com \\ Lucas Oliveira Souza \\ Universidade Estadual do Sudoeste da Bahia - UESB, Itapetinga, BA \\ Lucasgbi01@hotmail.com \\ Tatielle Pereira Silva \\ Universidade Federal de Alagoas - UFAL, Maceió, AL \\ tatielle.pereira@yahoo.com.br \\ Marcelo Franco \\ Universidade Estadual de Santa Cruz - UESC, Ilhéus, BA \\ mfranco@uesc.br
}

Resumo: Lipases (glicerol éster hidrolases EC 3.1.1.3) são enzimas capazes de catalisar naturalmente a hidrólise de ligações éster presentes em triacilgliceróis de cadeia longa, bem como reações de esterificação, interesterificação, transesterificação e aminólise em baixas condições de água. A capacidade de catalisar tais reações com alta eficiência e seletividade tornam estas enzimas potencialmente úteis em diversos processos biotecnológicos e industriais. Nas últimas décadas, a utilização de lipases microbianas em substituição aos catalisadores químicos convencionais tem sido fortemente incentivada. Entretanto, os altos custos de produção e as dificuldades operacionais destes biocatalisadores têm limitado bastante a sua utilização, impulsionando, portanto, muitas pesquisas relacionadas com a produção e utilização destas enzimas. Neste trabalho de revisão, pretendeu-se fornecer uma visão geral sobre as pesquisas que vêm sendo desenvolvidas envolvendo a produção, purificação e imobilização de lipases microbianas. Os processos de fermentação investigados para a produção, os principais tipos de micro-organismos e substratos empregados, bem como as estratégias para purificação e imobilização foram os principais focos desta revisão.

Palavras-chave: lipases; produção; fermentação; purificação; imobilização.

Abstract: Lipases (glycerol ester hydrolases EC 3.1.1.3) are enzymes capable to catalyze naturally the hydrolysis of ester bonds present in long-chain triglycerides, as well as to catalyze reactions of esterification, interesterification, transesterification and aminolysis in low water conditions. The ability to catalyze such reactions with high efficiency and selectivity make these enzymes potentially useful in various biotechnological and industrial processes. In recent decades, a use of microbial lipases in place of conventional chemical catalysts has been strongly encouraged. However, the high costs of production and operational difficulties of these biocatalysts has limited its use. This fact has boosting many research related

Recebido em 14-12-2016 - Aceito em 01/03/2018

\begin{tabular}{lllll} 
RECEN & $20(1)$ & p.30-53 jan/jun & 2018 & DOI:10.5935/RECEN.2018.01.03 \\
\hline
\end{tabular}


to the production and use of this enzymes. In this review, it was intended to provide an overview of the researches that have been developed involving the production, purification and immobilization of microbial lipases. The fermentation processes investigated for the production, the main types of microorganisms and substrates used, as well as the strategies for purification and immobilization were the main focuses of this review.

Key words: lipases; production; fermentation; purification; immobilization.

\section{Introdução}

As enzimas são importantes catalisadores biológicos indispensáveis em processos biotecnológicos, principalmente por catalisarem reações de modo seletivo e rápido [1]. Do ponto de vista da ciência química e biológica, as enzimas são caracterizadas como proteínas, com exceção das ribozimas, sendo formadas por aminoácidos ligados por ligações peptídicas covalentes. As suas estruturas conformacionais, estabilidade e atividade dependem fortemente das condições do meio, como, por exemplo, $\mathrm{pH}$ e temperatura [2].

Atualmente, cerca de 200 enzimas são utilizadas comercialmente. Dentre estas, as enzimas hidrolíticas somam aproximadamente $75 \%$ das enzimas utilizadas em processos industriais [3]. Em relação ao mercado global de vendas de enzimas, até a década de 1960 as vendas totais eram de apenas alguns milhões por ano. Após a melhor compreensão da bioquímica dos processos de produção, que envolve os processos de fermentação e métodos de recuperação, além dos avanços nos métodos de uso e o aumento da demanda por novos biocatalisadores, esse mercado tem crescido espetacularmente [4], atingindo cerca de US\$ 4,6 bilhões e US $\$ 4,9$ bilhões em 2014 e 2015, respectivamente, devendo aumentar de cerca de US $\$ 5,0$ bilhões em 2016 para US $\$ 6,3$ bilhões em 2021 [5].

De acordo com um relatório recente da Novoenzymes [6], companhia com uma quota estimada em $48 \%$ do mercado global de enzimas, as indústrias de alimentos e de produtos domésticos estão entre as mais importantes em termos de uso de enzimas, seguido pela indústria de bioenergia, alimentação animal, farmacêutica e outros setores técnicos (Figura $1)$.

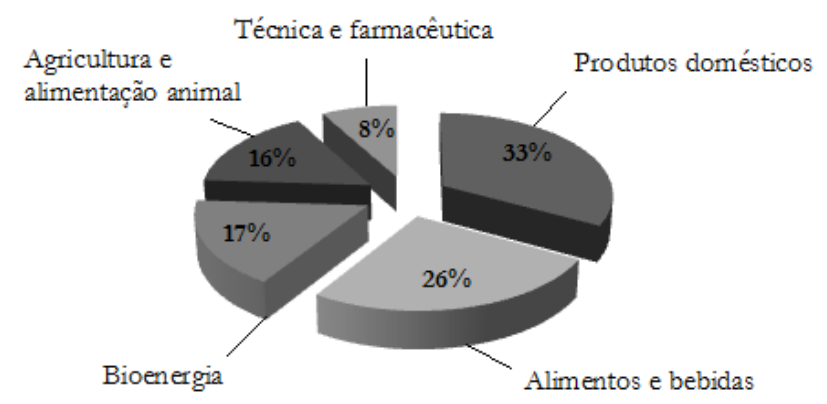

Figura 1. Distribuição do Mercado Global de enzimas industriais. Fonte: Novoenzymes [6]

Dentre as enzimas que participam do grande volume de vendas no mercado, as lipases (glicerol éster hidrolases E. C. 3.1.1.3) se classificam em terceiro lugar, ficando atrás apenas das proteases e das amilases [7]. Lipases podem ser utilizadas na indústria de alimentos 
Revista Ciências Exatas e Naturais, Vol.20, nº.1, Jan/Jun, 2018

(aditivos para modificação de aromas), farmacêutica (medicamentos), química fina (síntese de ésteres), produção de detergentes (hidrólise de gorduras), tratamentos de águas residuais (decomposição de substâncias oleaginosas), produção de biodiesel, bem como em ensaios biomédicos $[9,10]$.

Nos últimos anos, visando minimizar a formação de produtos indesejáveis durante os processos reacionais e, em geral, atender aos conceitos da química verde, a utilização de lipases em processos industriais tem sido fortemente encorajada em substituição aos processos químicos convencionais [10,11]. Entretanto, os altos custos envolvidos e as dificuldades operacionais para produção e utilização destas enzimas, frequentemente, limitam seu uso [12]. A fim de solucionar os problemas supracitados, e outros interesses, estudos envolvendo lipases vêm apresentando elevado crescimento. Este fato pode ser confirmado pelo número crescente de publicações apresentadas pela base de dados Web of Science utilizando como caractere de busca a palavra-chave "lipase" para o intervalo de anos de 2006 a 2016 (Figura 2).

Diante desta crescente investigação, o presente trabalho teve como objetivo revisar a literatura acerca da obtenção de lipases microbianas, ressaltando suas principais características, as técnicas de fermentação utilizadas durante a sua produção, os principais tipos de microorganismos e substratos empregados, bem como os métodos empregados para a purificação e imobilização.

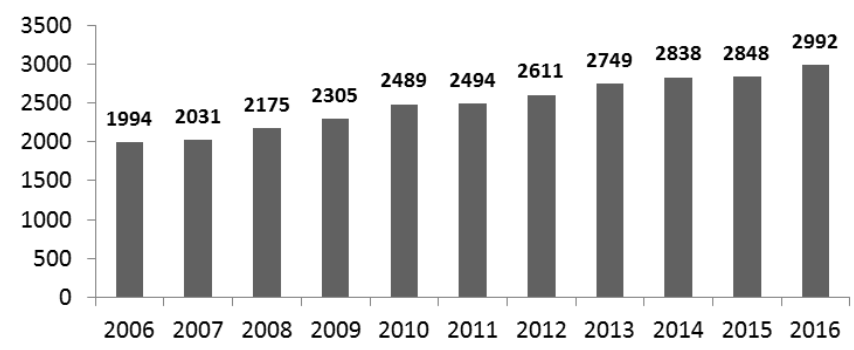

Figura 2. Número de publicações em jornais científicos durante o período de 2005 a 2014 utilizando a palavra-chave "lipase". Fonte: Web of Science.

\section{Propriedades e características das lipases}

As lipases são relatadas como proteínas monoméricas amplamente distribuídas na natureza (podem ser de origem animal, vegetal e microbiana) que pertencem à classe das hidrolases e possuem como principal função biológica a capacidade de catalisar a hidrólise de ligações éster presentes em triacilgliceróis para formar ácidos graxos livres, diacilgliceróis, monoacilgliceróis e glicerol. Além de catalisarem naturalmente reações de hidrólise, são também capazes de catalisar reações de esterificação, transesterificação (acidólise e alcoólise), interesterificação e aminólise em ambientes não aquosos $[13,14]$.

A principal característica física das lipases é sua baixa solubilidade em água. A capacidade de catalisar a hidrólise de ésteres de ácidos graxos insolúveis em água, inclusive a 
hidrólise de ésteres de cadeia longa, é o que as distingue das esterases. Além disso, as lipases atuam na interface óleo/água, já as esterases agem em ésteres solúveis em água [15].

A estrutura química e as propriedades cinéticas das lipases variam dependendo da fonte. Entretanto, a determinação das estruturas tridimensionais de muitas lipases por cristalografia de raios $\mathrm{X}$ tem revelado características comuns entre estas enzimas, que incluem: (a) possuem uma estrutura que é composta por um núcleo de fitas $\beta$, predominantemente paralelas, rodeadas por $\alpha$-hélices; (b) sítio ativo formado por uma tríade catalítica constituída pelos aminoácidos serina, ácido aspártico (ou glutâmico) e histidina; (c) presença de uma superfície entrelaçada, denominada de tampa (ou borda), composta por uma sequência de peptideos $\alpha$-hélice anfifílicos que cobrem o sítio ativo [16].

A atividade catalítica das lipases depende de diversos fatores que envolvem desde o substrato até as condições do meio de reação. Em relação ao substrato, a atividade lipolítica depende, principalmente, da posição do ácido graxo no esqueleto glicerol, do comprimento da cadeia do ácido graxo e de seu grau de insaturação. Dessa forma, as lipases apresentam especificidade, regiosseletividade, quimiosseletividade e enâncio-seletividade [17].

De acordo com Cortez et al [19], no que diz respeito a sua atuação sobre determinada região do triacilglicerol, as lipases podem ser classificadas em três grupos: (a) Lipases não específicas: não apresentam especificidade com relação à natureza do grupo acil ou à posição em que está esterificado. São enzimas que catalisam a hidrólise completa das moléculas de triacilglicerol, de forma aleatória, para formar glicerol e ácidos graxos livres (Figura 3a). Monoacilgliceróis e diacilgliceróis são formados como intermediários na mistura reacional; (b) Lipases 1,3 específicas: catalisam a liberação de ácidos graxos especificamente nas posições 1 e 3 dos triacilgliceróis e formam produtos diferentes daqueles obtidos por lipases não regiosseletivas (Figura 3b) e (c) Lipases ácido graxo específicas: catalisam a hidrólise de ésteres cujos ácidos graxos são de cadeia longa insaturada, contendo dupla ligação cis no carbono 9 (Figura 3c). Este tipo de especificidade não é muito comum entre as lipases.

Geralmente, as lipases apresentam massa molecular variando entre 19 a $75 \mathrm{kDa}$, dependendo da fonte. Em relação ao meio de atuação, a atividade das lipases dependem fortemente do $\mathrm{pH}$ e da temperatura. Algumas dessas enzimas são estáveis em uma ampla variação de $\mathrm{pH}$, normalmente, entre 4 e 9. A faixa ótima de temperatura em relação à atividade pode variar entre 30 e $40^{\circ} \mathrm{C}$, no entanto, algumas lipases têm mostrado níveis de estabilidade moderado em temperaturas extremas, como, por exemplo, 5 e $70^{\circ} \mathrm{C}[20,21]$. As lipases normalmente não requerem cofatores, mas cátions divalentes, tal como o cálcio, tende a estimular sua atividade. Geralmente, são drasticamente inibidas pela presença de $\mathrm{Co} 2+$, $\mathrm{Ni} 2+, \mathrm{Hg} 2+$ e $\mathrm{Sn} 2+$ e ligeiramente inibidas por $\mathrm{Zn} 2+, \mathrm{Mg} 2+$ e EDTA (ácido etilenodiamino tetra-acético) [22].

\section{Fonte de lipases microbianas}

Enzimas lipolíticas são amplamente encontradas na natureza (animais, plantas e microorganismos). No entanto, lipases obtidas a partir de fontes microbianas vêm recebendo maior atenção industrial por causa de suas interessantes características, tais como menor custo de produção, ação em condições brandas, estabilidade e alta especificidade ao substrato. Estas características têm levado a sua aplicação em vários processos catalíticos industrialmente importantes [23].

Muitos micro-organismos são conhecidos como potenciais produtores de lipases. Fazem parte desta categoria os fungos, leveduras e bactérias (Grã-positivas e Grã-negativas), sendo 
Revista Ciências Exatas e Naturais, Vol.20 , nº.1, Jan/Jun, 2018

(a)

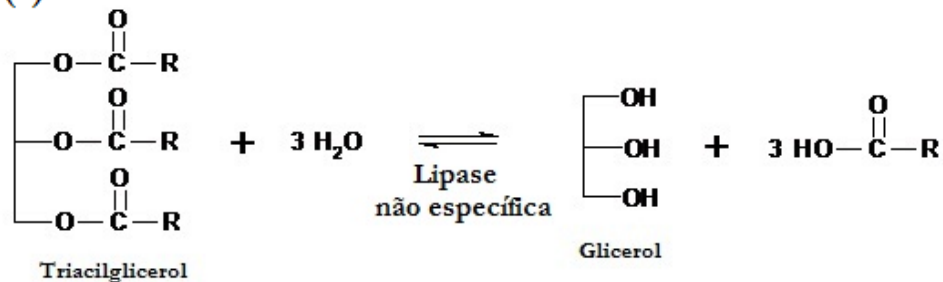

(b)
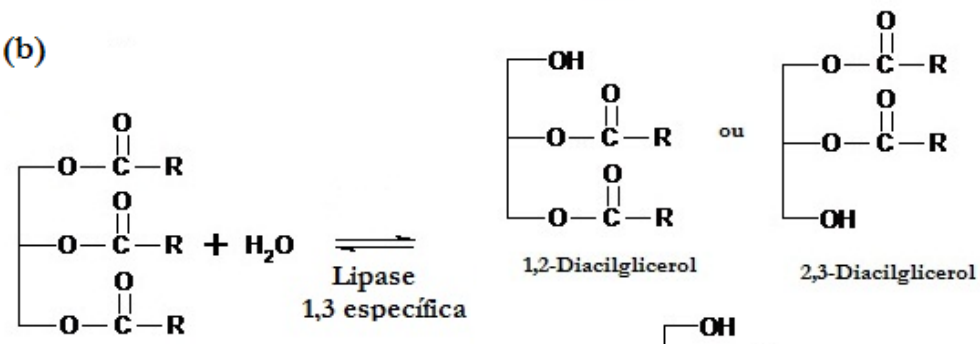

Triacilglicerol

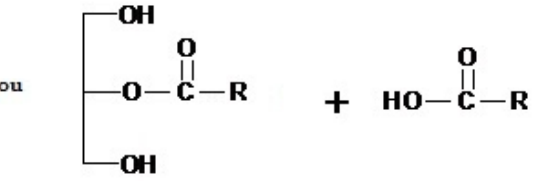

(c)

2-Monoacilglicerol

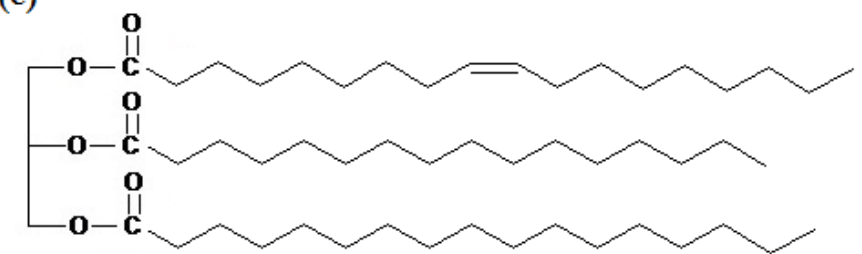

Triacilglicerol

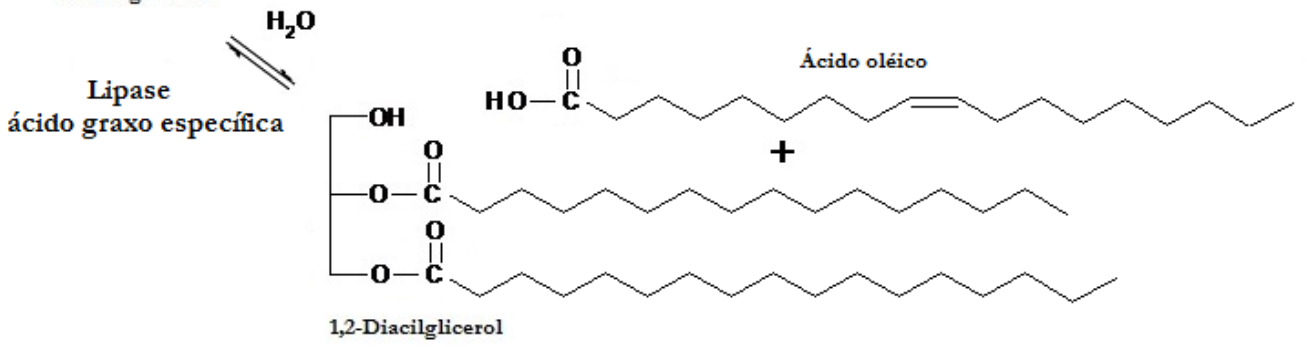

Figura 3. Esquemas representativos para a hidrólise de triacilgliceróis catalisada por (a) lipase não específica, (b) lipase 1,3 específica e (c) lipase ácido graxo específica. Adaptado de: Kapoor e Gupta [16]; Jensen [18].

que as lipases produzidas por estes micro-organismos são, em sua maioria, consideradas extracelulares [24].

As enzimas lipolíticas amplamente empregadas em aplicações biotecnológicas e em síntese orgânica são as obtidas a partir de fungos e bactérias [25]. Fungos normalmente são mais preferenciais devido a maior produção de enzimas extracelulares, o que facilita a extração do 
meio de fermentação, além da expectativa crescente do seu emprego como biocatalizadores na forma de células integrais, o que simplifica e pode reduzir o custo dos processos reacionais nos quais são utilizados $[26,27]$. Uma lista com os tipos mais comuns de micro-organismos produtores de lipases é apresentada na tabela 1.

Tabela 1. Alguns micro-organismos citados como fonte de lipase.

\begin{tabular}{|c|c|}
\hline Fonte & Microrganismos \\
\hline Fungos & $\begin{array}{l}\text { Penicillium citrinum, Penicillium restrictum, Penicillium simplicissimum, Pe- } \\
\text { nicillium verrucosum, Rhizopus arrhizus, Rhizopus chinensis, Rhizopus ho- } \\
\text { mothallicus, Rhizopus oryzae, Rhizopus sp., Aspergillus sp., Aspergillus car- } \\
\text { neus, Aspergillus niger, Geotrichum sp., Geotrichum candidum, Colletotrichum } \\
\text { gloesporioides. }\end{array}$ \\
\hline Leveduras & $\begin{array}{l}\text { Rhodotorula mucilaginosa, Yarrowia lipolytica, Candida utilis, Candida rugosa, } \\
\text { Candida artictica, Candida cylindracea, Candida sp., Trichosporon asahii, Au- } \\
\text { reobasidium pullulans, Saccharomyces cerevisiae, Williopsis californica. }\end{array}$ \\
\hline Bactérias & $\begin{array}{l}\text { Pseudomonas sp., Pseudomonas aeruginosa, Acinetobacter radioresistens, Ba- } \\
\text { cillus stearothermophilus, Bacillus sp., Bacillus coagulans, Bacillus subtilis, } \\
\text { Staphylococcus caseolyticus, Burkholderia cepacia, Burkholderia multivorans, } \\
\text { Serratia rubidaea. }\end{array}$ \\
\hline
\end{tabular}

Adaptado de: Treichel et al [27].

Em relação ao rendimento da produção enzimática, os fungos e leveduras são apontados como os preferenciais. Lipases fúngicas comercialmente importantes são, geralmente, obtidas de espécies dos gêneros Rhizopus, Aspergillus, Penicillium, Geotrichum, Mucor e Rhizomucor. Dentre estes, os gêneros Aspergillus e Penicillium têm sido indicados como potenciais em termos de rendimento de produção; espécies tais como A. alliaceus, A. candidus, A. carneus, A. fischeri, A. niger, A. ochraceus, A. parasiticus, A. sundarbanii, A. terreus, A. versicolor, P. aurantiogriseum, P. brevicompactum, P. camemberti, P. chrysogenum I, P. coryrnbiferum I, P. crustosum, P. egyptiacum, P. expansum e P. spiculisporum apresentaram altos níveis de produção de enzimas lipolíticas [28].

Dentre as leveduras, o gênero Candida tem sido bastante investigado. Lipases produzidas por C. rugosa e C. antarctica são amplamente utilizadas pela indústria devido a alta atividade em processos de hidrólise e síntese [29, 30,31]. Outras leveduras que também têm sido consideradas importantes produtoras de lipases são: Saccharomyces cerevisiae, Yarrowia lipolytica, Trichosporon asahii, Candida tropicalis, Candida curvata, Candida cylindraceae, Candida deformans, Candida parapsilosis, Candida utilis, Candida valida, Candida viswanathii, Galactomyces geotricum, Arxula adeninivorans, Trichosporan fermantans, Rhodotorula mucilaginosa, Aureobasidium pullulans [32].

Os gêneros Bacillus, Pseudomonas e Burkholderia são apontados como importantes produtores de lipase dentre os gêneros bacterianos. Bacillus subtilis, Bacillus pumilus, Bacillus licheniformis, Bacillus coagulans, Bacillus stearothermophilus, Bacillus alcalophilus, Pseudomonas sp., Pseudomonas aeruginosa, Burkholderia multivorans e Burkholderia cepacia têm sido relatadas como potenciais fontes de lipase [33]. Dentre os micro-organismos em geral, as bactérias têm sido as mais investigadas para a produção de lipases adaptadas ao frio. Bacillus sphaericus, Pseudomonas fragi, Pseudomonas fluorescens, Morexella sp., Acinetobacter sp., Aeromonas hydrophila, Achromobacter lipolyticum, Psychrobacter okhotskensis, 
Revista Ciências Exatas e Naturais, Vol.20, nº.1, Jan/Jun, 2018

Photobacterium lipolyticum, Staphylococcus epidermidis e Serratia marcescens são exemplos de cepas investigadas para produção de lipase em temperaturas tão baixas quanto $5^{\circ} C[28]$.

Embora seja conhecido um grande número de micro-organismos produtores de lipase, nem todos são adequados para produção em escala comercial. Características do microorganismo, tais como alta produtividade, facilidade de manipulação e capacidade de produzir uma ampla variedade de enzimas extracelulares; bem como as características das enzimas produzidas, tais como tolerância a variações de temperatura e pH, tolerância a emulsificação, surfactantes, e capacidade de armazenamento, são algumas das considerações importantes na seleção de micro-organismos para a produção de lipases comerciais [34, 35]. Algumas lipases comerciais bem como as companhias fornecedoras são apresentadas na tabela 2 .

Tabela 2. Algumas lipases de origem microbiana disponíveis comercialmente.

\begin{tabular}{|c|c|c|}
\hline Fonte & Nome comercial & Fornecedores \\
\hline \multicolumn{3}{|l|}{ Bactérias } \\
\hline Pseudomonas cepacia & Lipase SL & Amano \\
\hline Psudomonas menodocina & Lumafast & Genencor International \\
\hline Alcaligenes sp. & Lipase PL & Meito Sangyo, Co. \\
\hline Chromobacterium viscosum & Lipase CV & Genzyme \\
\hline \multicolumn{3}{|l|}{ Fungos } \\
\hline Aspergillus niger & $\begin{array}{l}\text { Lipase DS } \\
\text { Lipase }\end{array}$ & $\begin{array}{l}\text { Amano } \\
\text { Sigma }\end{array}$ \\
\hline Penicillium sp. & LipomodTM 621P-L621 & Biocatalysts \\
\hline Penicillium roqueforti & LipomodTM 338P-L338P & \\
\hline Rhizopus oryzae & $\begin{array}{c}\text { Lipopan }^{\circledR} \mathrm{F}^{\mathrm{a}} \\
\text { LipomodTM 627PL627P } \\
\text { LipomodTM 36P-L036P }\end{array}$ & $\begin{array}{c}\text { Novozyme } \\
\text { Biocatalysts }\end{array}$ \\
\hline Geotrichum candidum & SP 524 Lipolase & Nova Nordisk \\
\hline Mucor javanicus & Lipase M "Amano" 10 & Amano \\
\hline Rhizomucor miehei & Palatase $^{(B) a}$ & Novozyme \\
\hline \multicolumn{3}{|l|}{ Leveduras } \\
\hline Candida cylindracea & $\begin{array}{l}\text { Lipase MY } \\
\text { Resinase }^{\mathbb{B} a}\end{array}$ & $\begin{array}{c}\text { Meito Sangyo, Co. } \\
\text { Novozyme }\end{array}$ \\
\hline Candida rugosa & Lipase AY "Amano" 30 & Amano \\
\hline Candida antarctica & $\begin{array}{l}\text { Novozym }^{\circledR} 435^{\mathrm{a}} \\
\text { Noopazyme }^{\circledR a}\end{array}$ & Novozyme \\
\hline
\end{tabular}

Fonte: Salihu et al [29]; de Souza Vandenberghe et al [3].

\section{Produção de lipases microbianas}

As principais técnicas utilizadas para a produção de lipases microbianas são a fermentação submersa (FS) e a fermentação em estado sólido (FES). A FS consiste em um bioprocesso que ocorre na presença de excesso de água. Durante a FS os micro-organismos são suspensos em um meio líquido contendo nutrientes dissolvidos necessários para seu desenvolvimento e síntese de produtos de interesse [36]. Em contrapartida, a FES consiste 
no cultivo de micro-organismos sobre suportes sólidos húmidos, inertes ou em substratos insolúveis que podem ser utilizados como fonte de nutrientes e energia. Neste caso, o bioprocesso é realizado na ausência ou quase ausência de água livre, simulando o ambiente natural que muitos micro-organismos estão adaptados [37].

Estima-se que aproximadamente $90 \%$ da produção de enzimas industriais seja realizada por FS [38], cujo processo apresenta notáveis vantagens em relação à instrumentação para produção em larga escala, controle das condições de cultivo (monitoramento de temperatura, $\mathrm{pH}$, oxigênio dissolvido, concentração de soluto), separação da biomassa após o processo fermentativo, aeração e mistura [39]. Entretanto, apresenta uma maior probabilidade de contaminação do meio durante o processo devido a maior quantidade de água utilizada e, normalmente, necessita de uma etapa a mais de concentração para processos que evolvem a produção de enzimas extracelulares. Além disso, a produção de enzimas por FS, geralmente, envolve altos custos $[40,41]$.

A maioria das lipases produzidas por FS podem também ser produzidas por FES. A capacidade de fornecer uma alta produtividade enzimática, menor demanda por energia para esterilização, concentração mais elevada e estabilidade do produto final, menor geração de águas residuais e melhor utilização de resíduos agro-industriais como matéria prima de baixo custo, torna a FES uma técnica atrativa do ponto de vista econômico e ambiental $[42,39]$. Por outro lado, a produção em larga escala de enzimas por esta técnica geralmente presenta problemas que precisam ser superados, principalmente, às dificuldades encontradas no controle de alguns parâmetros que governam o processo de fermentação. Este fato pode ser observado pela limitada quantidade de trabalhos disponibilizados na literatura sobre designs de biorreatores para produção de enzimas por FES em maior escala [43, 44].

Estudos de produção de lipases por FS e FES têm focado principalmente na seleção de micro-organismos, controle das condições físico-químicas críticas ( $\mathrm{pH}$, temperatura, tempo de fermentação, difusão de oxigênio, entre outros), substratos, e suplementos que possam contribuir para alcançar rendimentos elevados de produção associado a custos reduzidos $[45,46]$.

Maia et al [47] utilizando um meio de cultura consistindo de 0,11\% de MgSO4.7H2O, 0,001\% de FeSO4, 0,015\% de $\mathrm{ZnSO} 4,0,015 \%$ de $\mathrm{NaCl}, 0,015 \%$ de $\mathrm{KH} 2 \mathrm{PO} 4$ e 0,3\% de NaNO3, avaliou a influência de óleos vegetais $(0,5 \%)$ e trioleína $(0,5 \%)$ como fonte de carbono em um processo de FS. O agente fermentador avaliado foi o fungo Fusarium Solani e melhor atividade lipolítica foi obtida quando utilizado o óleo de gergelim $(0,88 \mathrm{U} / \mathrm{mL})$, sob as condições de 120 horas de fermentação a $28^{\circ} \mathrm{C}$ e $120 \mathrm{rpm}$. Outras fontes de carbono como óleo de oliva, glicose e lactose, foram avaliadas por Freire et al [48] utilizando o fungo Penicillium restrictum em FS. Foi obtido um crescimento celular semelhante para o óleo de oliva e glicose, no entanto, empregando-se óleo de oliva foi obtida uma maior atividade lipolítica. Com a utilização de lactose não houve crescimento celular, sendo obtida baixa produção enzimática.

A utilização de óleos de oliva e girassol provenientes de frituras também tem sido avaliada por como substratos fonte de carbono para isolamento e produção de enzimas lipolíticas por FS. A utilização destes resíduos de forma eficiente já foi relatada para espécies dos gêneros Pseudomonas, Bacillus, Candida, Rhodococcus and Staphylococcus, sendo que Pseudomonas sp. apresentou melhores resultados, atividade de $2784 \mathrm{U} / \mathrm{L}$ [49]. Outros indutores tais como óleo de jojoba, óleo de milho e óleo de algodão; além de meios suplementares contendo coprodutos de cervejaria, extrato de malte e tween 80, têm sido frequentemente investigados $[50,51,52,53,54]$. Dentre as principais fontes orgânicas de nitrogênio investigadas na FS destacam-se extrato de levedura, peptonas, farelo de soja, uréia; e fontes inorgânicas como: 
Revista Ciências Exatas e Naturais, Vol.20, nº.1, Jan/Jun, 2018

(NH4)2SO4, NaNO3.e NH4Cl [55, 56, 57].

Um trabalho relevante voltado para a investigação da influencia da temperatura e $\mathrm{pH}$ sobre a produção de lipases por FS foi desenvolvido por Freire et al [?]. As temperaturas estudadas foram 25,30 e $37^{\circ} \mathrm{C}$, e a faixa de $\mathrm{pH}$ variou de 5,5 a 8 . O micro-organismo utilizado foi P. restrictum e foi obtido uma maior produção enzimática $(14 \mathrm{U} / \mathrm{mL})$ em 80 horas de fermentação sob a temperatura de $30^{\circ} \mathrm{C}$ e pH inicial de 5,5 , demonstrando que esses fatores podem exercer forte influencia na FS.

Amin et al [58] explorou a produção de lipases por Aspergillus melleus sob FES de diferentes resíduos agroindustriais: farelo de arroz, farelo de trigo, torta de óleo de semente de canola, casca de girassol e casca de amendoim. Dentre estes substratos, a torta de óleo de semente de canola foi considerada o melhor substrato para produção de lipases. Máxima atividade de lipase $(684,02 \mathrm{U} / \mathrm{g}$ de substrato) foi obtida utilizando óleo de oliva $3 \%$ como indutor, tempo de 96 horas de fermentação, temperatura de $30^{\circ} \mathrm{C}$ e umidade de $60 \%$.

Bhatti e Amin [59] relataram a produção de uma lipase alcalina por Ganoderma lucidum em FES utlizando torta de óleo de canola como substrato. A lipase purificada apresentou uma atividade de $33262 \mathrm{U} / \mathrm{mg}$ de proteínas e $\mathrm{pH}$ e temperatura ótimas de 8,5 e $35^{\circ} \mathrm{C}$, respectivamente.

Damaso et al [60] também avaliaram a produção de lipase por FES utilizando dois resíduos agroindustriais, farelo de trigo e sabugo de milho, bem como diferentes indutores provenientes do processo de refinamento do óleo de milho ou oliva (borra, estearina e ácidos graxos). O micro-organismo utilizado foi o fungo Aspergillus niger mutante 11T53A14 e os melhores resultados foram alcançados utilizando farelo de trigo como substrato e borra e estearina como indutores (62,7 e $37,7 \mathrm{U} / \mathrm{g}$ de substrato, respectivamente). Fleuri et al [61] também avaliaram a utilização de farelo de trigo sob a influência de indutores. Bons resultados foram alcançados utilizando o fungo Aspergillus sp. e farelo de soja suplementado com bagaço de cana-de-açúcar após um período de $96 \mathrm{~h}$ de fermentação (cerca de $11 \mathrm{U} / \mathrm{mL}$ ).

Diversos outros resíduos de origem agro-industrial também têm sido avaliados como substratos para produção de lipases por FES, podendo-se destacar palha de arroz, resíduos sólidos e líquidos do processamento do óleo de oliva, farelo de amêndoa, girassol, coco, soja e crambe, resíduo de babaçu, farelo de mamona, resíduos provenientes da extração do óleo de gergelim, amendoim, coco, semente de algodão, dentre outros (Tabela 3).

É difícil generalizar uma das técnicas, FS ou FES, como a mais apropriada para produção lipases. Além disso, torna-se difícil fazer uma comparação quantitativa uma vez que os métodos utilizados para determinação da atividade lipásica são diferentes [27]. Entretanto, é possível encontrar na literatura estudos que comparam a utilização destas técnicas sob condições específicas para produção de lipase por um mesmo micro-organismo. Oliveira et al. [69], por exemplo, avaliou a produção de lipase por Fusarium (complexo Gibberella fujikuroi) por FS e FES, sendo alcançando $3 \mathrm{U} / \mathrm{mL}$ e $5 \mathrm{U} / \mathrm{g}$, respectivamente, de atividade lipásica. Melhor custo/atividade enzimática foi alcançado quando utilizado a FES, apresentando um custo $87,27 \%$ menor quando utilizado a FS. Sarkar e Laha [70] avaliaram a produção de lipase extracelular por Aspergillus niger em FS e FES utilizando meio de cultura mineral e farelo de trigo, respectivamente. Foi alcançado $4,8 \mathrm{U} / \mathrm{mL}$ de atividade lipásica quando utilizado a FES e 1,46 U/mL quando utilizado a FS. Rajan e Nair [71] realizaram um estudo comparativo para a produção de lipase alcalina por Aspergillus fumigatus MTCC 9657 utilizando farelo de arroz desengordurado durante a FES e meio mineral durante a FS. Máxima produção de lipase $(8,13 \mathrm{U} / \mathrm{mL})$ foi obtido em um período de cultivo de 7 dias para a FES comparado com 4 dias para a FS. A lipase produzida por FES permaneceu estável por um período de 15, enquanto a lipase produzida por FS permaneceu por 5 dias. 
Nos últimos anos, com os avanços na área de engenharia genética, crescente interesse tem surgido na utilização de tecnologias de DNA recombinante para a produção de novas variantes de lipase que podem apresentar propriedades catalíticas e de estabilidade que melhor se adaptam às necessidades dos processos industriais. Outra característica atrativa é a possiblidade de aumento da reprodutibilidade e os rendimentos de produção enzimática $[3,17]$.

Robert et al. [72] avaliaram a produção recombinante de lipase B de Candida antarctica (rLipB) em Pichia pastoris, utilizando glicerina bruta proveniente da produção de biodiesel como fonte de carbono. A lipase produzida foi caracterizada e comparada com a lipase comercialmente disponível de Aspergillus niger, vendida pela Novozymes. rLip B mostrouse estável em pHs básicos e temperaturas inferiores a $55^{\circ} \mathrm{C}$, sendo as condições óptimas de $\mathrm{pH} 7,0$ e $30^{\circ} \mathrm{C}$. Os resultados indicaram a abordagem utilizada como uma alternativa viável para produzir rLipB utilizando glicerol bruto.

Jallouli et al. [73] avaliara, a produção recombinante de lipase Fusarium solani (FSL2) em Pichia pastoris para alcançar um alto rendimento de produção de lipase extracelular. A actividade máxima de lipase foi observada após $48 \mathrm{~h}$ de cultivo em meio de extrato de levedura-peptona-dextrose. Máxima atividade da lipase recombinante purificada foi alcançada na faixa de $\mathrm{pH} 8-9$ a $37^{\circ} \mathrm{C}$. A FSL2 apresentou notável estabilidade em $\mathrm{pH}$ até 12 e em temperaturas inferiores a $40^{\circ} \mathrm{C}$, sendo observado alta eficiência catalítica para triglicerídeos de cadeia média e longa.

\section{Purificação}

Após a fermentação, a enzima de interesse encontra-se misturada no meio com uma série de outros compostos que não são de interesse. A fim de separar o produto de interesse da mistura são empregados processos de purificação enzimática, cuja etapa constitui uma importante parte do processo biotecnológico para a produção de lipases com alta eficiência [74].

O principal interesse na purificação de lipases está associado à obtenção da enzima pura, para melhor estudo de suas características estruturais e bioquímicas, e a obtenção da enzima com maior atividade específica para aplicação em processos biotecnológicos [75]. Atualmente, as indústrias têm buscado estratégias de purificação que sejam mais baratas, rápidas, que apresentem alto rendimento e que sejam passíveis de operações em larga escala [76].

Diferentes estratégias podem ser utilizadas para recuperação e purificação de lipases, podendo envolver diferentes técnicas como: filtração, precipitação, separação por membranas, sistema aquoso bifásico, sistema micelar reverso, imunopurificação, além de métodos cromatográficos, como, por exemplo, cromatografia por afinidade, cromatografia de troca iônica e cromatografia de interações hidrofóbicas (tabela 4) [77]. Para a escolha dos métodos de purificação a serem utilizados deve ser levado em consideração o grau de pureza da enzima que se deseja alcançar, o tipo de aplicação e o custo total do processo.

Dentre as técnicas de separação a precipitação é uma das mais práticas. Cerca de $80 \%$ dos esquemas utilizados para purificação de lipases utilizam um passo de precipitação. Na precipitação ocorre a formação de agregados proteicos através da modificação do $\mathrm{pH}$, força iônica e temperatura do meio que podem ser alcançados pela adição de solventes orgânicos miscíveis, sais ou outros solutos. Após a formação dos agregados proteicos, os mesmos podem ser separados por filtração ou centrifugação. Dentre os agentes precipitantes, cerca de $60 \%$ dos processos empregam sulfato de amônio, $35 \%$ utilizam etanol, acetona ou ácido 
Revista Ciências Exatas e Naturais, Vol.20 , nº.1, Jan/Jun, 2018

Tabela 3. Alguns estudos envolvendo a utilização de resíduos agro-industriais para produção de lipase microbiana por FES.

\begin{tabular}{|c|c|c|c|c|}
\hline Micro-organismo & $\begin{array}{l}\text { Substratos investi- } \\
\text { gados/suplementos }\end{array}$ & $\begin{array}{l}\text { Condições } \\
\text { de máxima } \\
\text { produção }\end{array}$ & $\begin{array}{l}\text { Atividade } \\
\text { lipásica } \\
\text { máxima }\end{array}$ & Ref. \\
\hline Rizhopus oryzae & $\begin{array}{l}\text { Palha de arroz/ óleo de } \\
\text { oliva }(1,38 \%) ; \text { farelo de } \\
\text { soja }(1,27 \%)\end{array}$ & $\begin{array}{l}\text { Umidade } 60 \% \\
10^{6} \text { esporos } / \mathrm{g} ; \\
30^{\circ} \mathrm{C}\end{array}$ & $57,76 \mathrm{U} / \mathrm{g}$ & {$[62]$} \\
\hline Yarrowia lipolytica & $\begin{array}{l}\text { Resíduo de azeite } \\
\text { após pré-tratamento } \\
\text { alcalino/ extrato de } \\
\text { levedura }(3 \%)\end{array}$ & $\begin{array}{l}\text { Umidade } 55 \% \\
5 \times 10^{6} \quad \text { espo- } \\
\operatorname{ros} / \mathrm{g} ; \quad 30^{\circ} \mathrm{C} ; 4 \\
\text { dias }\end{array}$ & $40 \mathrm{U} / \mathrm{g}$ & {$[63]$} \\
\hline Penicillium sp. & $\begin{array}{l}\text { Farelo de soja/ uréia } \\
(3 \%) \text {; óleo de soja (1\%) }\end{array}$ & $\begin{array}{l}\text { Umidade } 55 \% ; \\
108 \text { esporos } / \mathrm{g} ; \\
27^{\circ} \mathrm{C} ; 120 \mathrm{~h} ; \mathrm{pH} \\
7\end{array}$ & $203,72 \mathrm{U} / \mathrm{g}$ & {$[9]$} \\
\hline Trichophyton sp. & $\begin{array}{l}\text { farelo de amêndoa, gi- } \\
\text { rassol, brassica, coco/ } \\
\text { óleo de amêndoa (1\%), } \\
\text { glicose }(1 \%) \text {, peptona } \\
(1 \%)\end{array}$ & $\begin{array}{lr}0,47 \quad \mathrm{~mL} & \mathrm{de} \\
\text { tampão } & \text { fos- } \\
\text { fato/g } & \mathrm{de} \\
\text { substrato; } 1 \mathrm{~mL} \\
\text { de solução de } \\
\text { esporos; } 26^{\circ} \mathrm{C} ; \\
\text { 48h; pH } 7\end{array}$ & $\begin{array}{l}76,42 \\
\mathrm{U} / \mathrm{mL} \\
\text { (amêndoa } \\
+\quad \text { giras- } \\
\text { sol }+ \\
\text { brassica) }\end{array}$ & {$[64]$} \\
\hline Fusarium sp. & $\begin{array}{l}\text { Farelo de crambe/ óleo } \\
\text { de oliva }(1 \%)\end{array}$ & $\begin{array}{l}\text { Umidade } 60 \% ; \\
10^{7} \text { esporos } / \mathrm{g} ; \\
28^{\circ} \mathrm{C} ; \quad 120 \mathrm{~h} ; \\
\mathrm{pH} 7\end{array}$ & $5 \mathrm{U} / \mathrm{g}$ & {$[65]$} \\
\hline Candida rugosa & $\begin{array}{l}\text { Resíduo de gerge- } \\
\text { lim; resíduo de coco; } \\
\text { resíduo de amendoim/ } \\
\text { meio mineral }\end{array}$ & $\begin{array}{l}\text { Umidade } 1: 3,23 \\
(\mathrm{~g} / \mathrm{mL}) ; 5 \% \text { de } \\
\text { inóculo após } 24 \\
\text { de cultivado; } \\
32,3{ }^{\circ} \mathrm{C} ; 60 \mathrm{~h}\end{array}$ & $\begin{array}{l}22,40 \text { U/g } \\
\text { (Resíduo } \\
\text { de gerge- } \\
\text { lim) }\end{array}$ & {$[66]$} \\
\hline $\begin{array}{l}\text { Penicillium brevi- } \\
\text { compactum }\end{array}$ & $\begin{array}{l}\text { Resíduo de babassu; } \\
\text { farelo de mamona/ } \\
\text { óleo de soja }(2 \%)\end{array}$ & $\begin{array}{l}\text { Umidade } 70 \% ; \\
10^{7} \text { esporos/g; } \\
30^{\circ} \mathrm{C} ; 96 \mathrm{~h}\end{array}$ & $\begin{array}{l}87,6 \quad \mathrm{U} / \mathrm{g} \\
\text { (farelo de } \\
\text { mamona) }\end{array}$ & {$[67]$} \\
\hline $\begin{array}{l}\text { Lasiodiplodia theo- } \\
\text { bromae }\end{array}$ & $\begin{array}{l}\text { Resíduos das semen- } \\
\text { tes de: coco, mamona, } \\
\text { algodão, mahua, nim, } \\
\text { amendoim, pongamia, } \\
\text { gergelim/ óleo de coco } \\
(0,98 \%) \text {; Triton X-100 } \\
(1,5 \%)\end{array}$ & $\begin{array}{l}\text { Umidade } 66,4 \% \\
10^{7} \text { esporos } / \mathrm{g} ; \\
30^{\circ} \mathrm{C} ; \quad 10 \text { dias; } \\
\mathrm{pH} 6,5\end{array}$ & $\begin{array}{l}698,1 \\
\text { U/g(resíduo } \\
\text { de coco) }\end{array}$ & [68] \\
\hline
\end{tabular}


Tabela 4. Estudos envolvendo técnicas de purificação de lipases microbianas.

\begin{tabular}{|c|c|c|c|c|}
\hline Fonte & Técnicas de purificação & $\begin{array}{l}\text { Fator de puri- } \\
\text { ficação/rendimento }\end{array}$ & $\begin{array}{l}\text { Caraterísticas } \\
\text { da lipase }\end{array}$ & Ref. \\
\hline $\begin{array}{l}\text { Bacillus pu- } \\
\text { milus RK31 }\end{array}$ & $\begin{array}{l}\text { Precipitação (sulfato de } \\
\text { amônio), cromatografia } \\
\text { de gel filtração (Sepha- } \\
\text { dex G200) e troca iônica } \\
\text { (DEAE-cellulose) }\end{array}$ & $186 / 18,76 \%$ & $\begin{array}{l}3525,6 \mathrm{U} / \mathrm{mg} \\
65,2 \mathrm{kDa}\end{array}$ & {$[78]$} \\
\hline $\begin{array}{l}\text { Penicillium } \\
\text { expansum } \\
\text { PED-03 }\end{array}$ & $\begin{array}{l}\text { Cromatografia de troca } \\
\text { iônica (DEAE-Sepharose) } \\
\text { e gel filtração (Sephacryl } \\
\text { S-200) }\end{array}$ & $81,8 / 19,8 \%$ & $\begin{array}{l}85,9 \mathrm{U} / \mathrm{mg} ; 28 \\
\mathrm{kDA}\end{array}$ & {$[79]$} \\
\hline $\begin{array}{l}\text { Pseudomonas } \\
\text { stutzeri } \\
\text { LC2-8 }\end{array}$ & $\begin{array}{l}\text { Precipiação (acetona) e } \\
\text { cromatografia de troca } \\
\text { iônica (DEAE-Sepharose } \\
\text { FF) }\end{array}$ & $21,2 / 32,8 \%$ & $\begin{array}{l}4760 \mathrm{U} / \mathrm{mg} ; 32 \\
\mathrm{kDa}\end{array}$ & {$[80]$} \\
\hline $\begin{array}{l}\text { Penicillium } \\
\text { camembertii } \\
\text { Thom PG-3 }\end{array}$ & $\begin{array}{l}\text { Precipitação (pH; etanol; } \\
\text { sulfato de amônio) e cro- } \\
\text { matografia de troca iônica } \\
\text { (DEAE-cellulose) }\end{array}$ & $19,8 / 8,7 \%$ & $\begin{array}{l}886 \quad \mathrm{U} / \mathrm{mg} ; \\
28,18 \mathrm{kDa}\end{array}$ & {$[50]$} \\
\hline $\begin{array}{l}\text { Pseudomonas } \\
\text { sp. CSD3 }\end{array}$ & $\begin{array}{l}\text { Sistema micelar reverso } \\
\text { (AOT/iso-octano) } \\
\text { traído com solução de } \\
\mathrm{NaCl} \text { e isopropanol }\end{array}$ & $15 / 80 \%$ & $\begin{array}{l}23 \mathrm{U} / \mathrm{mg} ; 18 \\
\mathrm{kDa}\end{array}$ & {$[81]$} \\
\hline $\begin{array}{l}\text { Rhizopu ory- } \\
\text { zae }\end{array}$ & $\begin{array}{l}\text { Precipitação (sulfato de } \\
\text { amônio); cromatografia de } \\
\text { troca iônica (SP Sepha- } \\
\text { rose) e gel filtração (Sepha- } \\
\text { dex G75) }\end{array}$ & $1200 / 22 \%$ & $\begin{array}{l}8800 \mathrm{U} / \mathrm{mg} ; 32 \\
\mathrm{kDa}\end{array}$ & {$[82]$} \\
\hline $\begin{array}{l}\text { Bacillus } \quad \text { sp. } \\
\text { ITP-001 }\end{array}$ & $\begin{array}{l}\text { Sistema aquoso bifásico } \\
\text { com base em sais de colina } \\
\text { (cloreto de colina, bitarta- } \\
\text { rato de colina e dihidroge- } \\
\text { nocitrato de colina) e te- } \\
\text { traidrofurano }\end{array}$ & $130,1 / 90 \%$ & $\begin{array}{ll}726548 & \mathrm{U} / \mathrm{mg} \\
54 \mathrm{kDa} & \end{array}$ & {$[83]$} \\
\hline
\end{tabular}


Revista Ciências Exatas e Naturais, Vol.20, nº.1, Jan/Jun, 2018

\section{$[84,85]$.}

Normalmente, as técnicas de precipitação são empregadas como uma primeira etapa de pré-purificação, devido ao fato de que apenas o emprego desta estratégia não garante alta pureza da enzima de interesse, sendo necessária a realização de etapas complementares utilizando métodos com maior capacidade de resolução. Contudo, há casos em que apenas a etapa de precipitação oferece um grau de pureza satisfatório, como na purificação de lipases de Cunninghamella verticillata, onde a utilização de acetona como agente precipitante forneceu um resultado melhor do que a separação por cromatografia [86, 87]. 
No trabalho de Borkar et al [88], foi necessário realizar a precipitação do extrato enzimático bruto de lipase de Pseudomonas aeruginosa 20 vezes com sulfato de amônio $(30 \%$ p/v), seguida da realização de duas etapas cromatográficas para obtenção de uma solução 98 vezes mais pura do que o extrato enzimático bruto. Esta situação indica que, normalmente, há a necessidade de mais etapas de purificação além da precipitação, sendo na maioria das vezes empregado métodos cromatográficos após esta etapa.

Dentre os métodos cromatográficos, a cromatografia de troca iônica tem sido a mais empregada, sendo utilizada em cerca de $67 \%$ dos esquemas de purificação analisados. O segundo método mais utilizado é a cromatografia de gel filtração seguido pela cromatografia de afinidade e cromatografia de interações hidrofóbicas [84].

Koblitz e Pastore [89] avaliando a utilização de cromatografia de troca iônica e de interação hidrofóbica para purificação de lipase de Rhizopus sp. observaram um fator de purificação de 3,9 e 6,8, respectivamente. Shaoxin e colaboradores [95] avaliou a purificação de lipase produzida por Bacillus cereus $\mathrm{C} 71$ utilizando a técnica de precipitação com sulfato de amônio até concentração de $60 \%$, seguido de cromatografia de interação hidrofóbica, além de cromatografia de troca iônica e aplicação em coluna de material monolítico polimérico. A lipase produzida teve um grau de purificação de 1902 vezes, com $18 \%$ de rendimento.

Altos valores de fator de purificação podem ser alcançados empregando-se técnicas sequenciais de precipitação e cromatografia. Normalmente, mais de três etapas de purificação são necessárias para obtenção de enzimas com alto grau de pureza [86].

Devido a natureza hidrofóbica das lipases, fenômenos de ativação interfacial e atividade em sistemas não-aquosos, algumas novas tecnologias têm sido propostas para a purificação destas enzimas. Dentre estas tecnologias podem-se destacar: sistemas bifásicos, sistema micelar reverso, separação utilizando membranas e imunopurificação [90, 91].

A formação de um sistema aquoso bifásico ocorre quando dois polímeros quimicamente diferentes e hidrossolúveis (por exemplo: polímero de polietileno glicol e dextrano), ou um polímero e um sal orgânico (por exemplo: fosfato) são misturados em água sob condições críticas de pressão, temperatura e composição dos constituintes. A partição de proteínas em sistemas bifásicos depende das propriedades físico-químicas da proteína como, por exemplo, a hidrofobicidade e a carga e o tamanho da mesma; além das propriedades do sitema bifásico, como pH e o tipo e a massa molecular do polímero. As principais vantagens da separação por sistemas bifásicos são a redução de volume necessário e a alta e rápida capacidade de separação [90].

A recuperação de enzimas pelo sistema micelar reverso é realizada por meio da utilização de tensoativos para formação de micelas em solventes apolares. Esta técnica baseia-se na propriedade que certos tensoativos têm de se auto-organizar formaçando agregados com um núcleo aquoso em seu interior, quando em meio orgânico, que possibilita a dissolução de enzimas. O processo de recuperação geral consiste em dois passos básicos: extração direta que envolve a absorção de proteínas de um solvente aquoso para o núcleo das micelas reversas em um solvente apolar; e um processo de extração das enzimas do núcleo das micelas reversas para outro solvente aquoso a ser recuperado. Apesar da possibilidade de recuperação de lipases por esta técnica, tem sido observadas limitações. Por exemplo, quanto maior a concentração de surfactante, maior a dificuldade de recuperação, além disso, a quantidade de solventes orgânicos que não provocam a desnaturação de enzimas são bastante limitados $[91,92]$.

A imunopurificação é uma das técnicas de purificação de proteínas mais eficientes e seletivas, consistindo de um sistema onde ocorrem ligações da proteína (enzima) a uma matriz ligante (anticorpo), promovendo assim a separação da enzima do meio. A principal 
Revista Ciências Exatas e Naturais, Vol.20, nº.1, Jan/Jun, 2018

desvantagem desta técnica é o alto custo. Porém, possui como vantagens um processo seguro, rápido e reprodutível [84]. No caso da técnica de separação por membranas, a mesma constitui-se atualmente como uma etapa no processo de purificação de enzimas, devido aos baixos fatores de purificação e rendimentos obtidos, além do alto custo e dificuldades operacionais envolvidas no processo.

\section{Imobilização}

A imobilização de enzimas tem sido considerada uma técnica bastante atrativa para a aplicação comercial de todos os tipos de enzimas. O principal interesse na utilização de enzimas imobilizadas está associado às vantagens oferecidas por esta técnica em comparação com a utilização de enzimas livres [93].

Dentre as vantagens apresentadas pela técnica de imobilização enzimática pode-se destacar a facilidade de separação das enzimas do meio reacional, o que possibilita a sua reutilização e diminui a possibilidade de contaminação por proteínas do produto final. Além disso, a imobilização fornece a possibilidade de aumento de atividade catalítica, estabilidade térmica, estabilidade a variações de $\mathrm{pH}$ e possibilidade de modulação da seletividade e especificidade enzimática, bem como a redução de problemas de inibição [94].

As lipases podem ser imobilizadas empregando-se a maioria dos métodos utilizados para imobilização de enzimas em geral [93]. Esses métodos estão divididos em: adsorção física a um suporte, ligação covalente a um suporte,confinamento e ligação cruzada [95]. Um esquema representativo destes métodos de imobilização é apresentado na Figura 4.

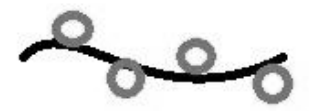

Adsorção física

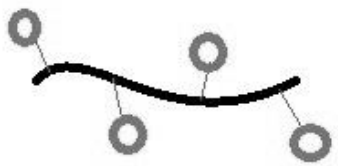

Ligação covalente

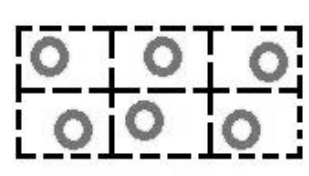

Confinamento

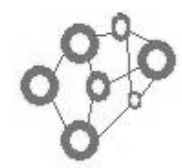

Ligação cruzada

Onzima - Suporte $\longrightarrow$ Ligante

Figura 4. Representação esquemática dos métodos de imobilização de enzimas.

De acordo com Hartmann e Kostrov [96], cada método de imobilização possui suas vantagens e desvantagens. A adsorção física pode ser considerada um procedimento barato, simples e bastante atrativo por não promover mudança conformacional da enzima, por outro lado, é susceptível a lixiviação das enzimas adsorvidas ao suporte. Já a imobilização por ligação covalente permite uma maior fixação da enzima ao suporte, evitando problemas como lixiviação. No entanto, este tipo de imobilização pode resultar em diminuição ou perda de atividade catalítica, devido à mudança conformacional da enzima. O método 
de ligação cruzada e/ou confinamento apresentam como principais vantagens a estabilização em relação a condições severas de reação (por exemplo: pH extremo), não necessidade de elevada pureza enzimática e nenhuma ou mínima mudança conformacional da enzima. No entanto, é considerado um processo complicado que normalmente requer mais de um passo experimental, necessita de compostos químicos tóxicos (por exemplo: glutaraldeído) e provoca a diminuição da taxa de difusão dos substratos/produtos devido ao reduzido tamanho do poro.

De acordo com Malcata et al [97], diferentes fatores devem ser levados em consideração no momento da escolha de um método de imobilização. Dentre estes fatores pode-se destacar: o custo do processo, a toxidade dos reagentes utilizados, as características de regeneração e inativação do produto e as propriedades finais desejadas para a enzima imobilizada.

Além da enzima, o suporte para a imobilização enzimática exerce uma grande contribuição para o desempenho do biocatalisador. Na literatura podem ser encontrados diferentes tipos de suportes empregados para imobilização de enzimas [95, 98]. A tabela 5 apresenta a classificação dos principais tipos de suportes, de acordo a sua composição, utilizados para imobilização de enzimas. A escolha e aplicação de um determinado suporte devem ser

Tabela 5. Classificação quanto à composição dos principais tipos de suportes empregados para imobilização enzimática.

\begin{tabular}{|c|c|c|}
\hline $\begin{array}{l}\text { Suporte } \\
\text { Inorgânico }\end{array}$ & $\begin{array}{l}\text { Minerais } \\
\text { Areia, pedra-pomes, } \\
\text { bentonita, nanofi- } \\
\text { bra, Argila }\end{array}$ & $\begin{array}{l}\text { Fabricados } \\
\text { Sílica, vidros, } \\
\text { cerâmicas, óxidos } \\
\text { metálicos, alu- } \\
\text { minossilicatos, } \\
\text { nanopartículas de } \\
\mathrm{Fe}_{3} \mathrm{O}_{4}\end{array}$ \\
\hline $\begin{array}{l}\text { Suporte } \\
\text { Orgânico }\end{array}$ & $\begin{array}{l}\text { Naturais } \\
\text { Amido, celulose, } \\
\text { quitina, albumina, } \\
\text { colágeno, gelatina, } \\
\text { seda, bagaço de } \\
\text { cana-de-açucar, } \\
\text { fibra de coco }\end{array}$ & $\begin{array}{l}\text { Sintéticos } \\
\text { Nylon, poliesti- } \\
\text { reno, polivinilos, } \\
\text { poliacrilatos }\end{array}$ \\
\hline
\end{tabular}

Adaptado de: Carvalho et al [95].

precedidas pela avaliação minuciosa das principais características de um suporte, que são: área superficial, insolubilidade, permeabilidade, capacidade de regeneração, composição e morfologia, resistência mecânica, resistência a ataque microbiano e, principalmente, o custo [99].

A busca por novos suportes materiais que apresentem melhores características para imobilização de enzimas tem levado ao desenvolvimento de materiais híbridos. Os suportes híbridos são materiais constituídos pela combinação de componentes orgânicos e inorgânicos, que apresentam propriedades diferentes daqueles materiais que lhe deram origem. Os materiais híbridos orgânico-inorgânicos têm sido apontados como fornecedores de novas características que melhoram as propriedades do material, tendendo a apresentar tanto as vantagens dos materiais orgânicos (leveza, flexibilidade e boa moldabilidade) como as vanta- 
Revista Ciências Exatas e Naturais, Vol.20 , nº.1, Jan/Jun, 2018

gens dos materiais inorgânicos (alta resistência mecânica, estabilidade ao calor e resistência química) [100]

\section{Considerações finais}

Os resultados discutidos nesta revisão demonstram claramente a ampla utilidade das lipases bem como os esforços realizados para promover o desenvolvimento dos processos de produção, purificação e imobilização destas enzimas, a fim de superar os altos custos envolvidos nestas etapas e as dificuldades operacionais para produção em larga escala.

Dentre os principais esforços para a superação das limitações dos processos atuais de produção e utilização de lipase, destaca-se a procura por potenciais organismos produtores, matéria prima de baixo custo, técnicas alternativas de purificação, técnicas e materiais alternativos para imobilização.

Dentre os organismos produtores, os microrganismos têm sido apontados como potenciais fontes de lipases. Em relação às técnicas de produção, a fermentação em estado sólido tem mostrado ser uma alternativa bastante eficiente, principalmente devido à possibilidade de utilização de resíduos agroindustriais como matéria prima barata. No entanto, estudos mais detalhados sobre a sua aplicação em larga escala devem ser realizados.

No âmbito das técnicas de purificação de lipases, intensa investigação tem sido guiada para o desenvolvimento e emprego de alternativas que apresentem baixo custo, alto rendimento e maior pureza. Para a facilidade de reaproveitamento e na tentativa de manter as características catalíticas das lipases, novas técnicas e materiais para imobilização vem sendo desenvolvidos e avaliados.

Processos catalíticos baseados em lipases tem um futuro promissor com base nos benefícios econômicos e ambientais que a utilização destas enzimas pode fornecer. No entanto, a taxa de progresso é lenta, uma vez que existe muita complexidade na utilização destes catalisadores.

\section{Referências}

[1] PATEL, A. K.; SINGHANIA, R. R.; PANDEY, A. Novel enzymatic processes applied to the food industry. Curr Opin in Food Sci, vol. 7, p. 64-72, 2016.

[2] ZAHA, A.; FERREIRA, H. B.; PASSAGLIA, L. M. Biologia Molecular Básica. $5^{\text {a }}$ Ed. Porto Alegre. Artmed Editora, 2014.

[3] DE SOUZA VANDENBERGHE, L. P.; DE CARVAlHO, J. C.; LIBARDI, N.; RODRIGUES, C., SOCCOL, C. R. Microbial Enzyme Factories: Current Trends in Production Processes and Commercial Aspects. Agro-Industrial Wastes as Feedstock for Enzyme Production: Apply and Exploit the Emerging and Valuable Use Options of Waste Biomass, p. 1, 2016.

[4] MONDAL, S.; BAKSI, S.; KORIS, A.; VATAI, G. Journey of enzymes in entomopathogenic fungi. Pacific Sci Rev A: Nat Sci Eng, vol. 18, n. 2, p. 85-99, 2016.

[5] BCC RESEARCH. 2017. Global Markets for Enzymes in Industrial Applications. Disponível em: http://www.bccresearch.com/report/BIO030j.html. Acesso em 02/05/20157. 
[6] THE NOVOZYMES REPORT. 2016. Disponível em: https://report2016.novozymes.com/-/media/Account-PDF/PDF section/NovozymesReport2016.ashx. Acesso em 10/05/2017.

[7] CARVAlHO, T.; FINOTELli, P. V.; BONOMO, R. C.; FRANCO, M..;AMARAL, P. F. Evaluating aqueous two-phase systems for Yarrowia lipolytica extracellular lipase purification. Process Biochem, vol. 53, p. 259-266, 2017.

[8] RIGO, E.; NINOW, J. L.; DI LUCCIO, M.; OLIVEIRA, J. V.; POLlONI, A. E.; REMONATTO, D.; ARBTER, F.; VARDANEGA, R.; OLIVEIRA, D.; TREICHEL, H. Lipase production by solid fermentation of soybean meal with different supplements. LWT Food Sci Technol, vol. 43, p. 1132-1137, 2010.

[9] RAmnath, L.; SITHOlE, B.; GOVINDEN, R. Classification of lipolytic enzymes and their biotechnological applications in the pulping industry. Can J Microbiol, n. ja, 2016.

[10] BANSODE, S. R.; RATHOD, V. K. An Investigation of lipase catalysed sonochemical synthesis: A review. Ultrason Sonochem, vol. 38, p. 503-529, 2017.

[11] LERIN, L. A., LOSS, R. A., REMONATto, D., ZENEVICZ, M. C., BAlEN, M., NETTO, V. O., NINOW, J. L.; TRENTIN, C. M.; OLIVEIRA, J. V.; DE OLIVEIRA, D. A review on lipase-catalyzed reactions in ultrasound-assisted systems. Bioprocess Biosyst Eng, vol. 37, n. 12, p. 2381-2394, 2014.

[12] VETEIKYT, A.; ŠIEKŠTEL, R.; TVASKA, B.; MATIJOŠYT, I. Sequential application of waste whey as a medium component for Kluyveromyces lactis cultivation and a co-feeder for lipase immobilization by CLEA method. Appl Microbiol Biotechnol, vol. 101, n. 9, p. 3617-3626, 2017.

[13] GOPINATH, S. C.; ANBU, P.; LAKSHMIPRIYA, T.; HILDA, A. Strategies to characterize fungal lipases for applications in medicine and dairy industry. BioMed Res Int, vol. 2013, 2013.

[14] GOdOY, M. G.; GUTARRA, M. L. E.; CASTRO, A. M.; MACHAdO, O. L. T.; FREIRE, D. M. G. Adding value to a toxic residue from the biodiesel industry: production of two distinct pool of lipases from Penicillium simplicissimum in castor bean waste. J Ind Microbiol Biotechnol, vol. 38, p. 945-953, 2011.

[15] GUNCHEVA, M.; TASHEV, E.; ZHIRYAKOVA, D.; TOSHEVA, T.; TZOKOVA, N. Immobilization of lipase from Candida rugosa on novel phosphorous-containing polyurethanes: Application in wax ester synthesis. Process Biochem, vol. 46, p. 923-930, 2011.

[16] KAPOOR, M.; GUPTA, M. N. Lipase promiscuity and its biochemical applications. Process Biochem, vol. 47, n. 4, p. 555-569, 2012.

[17] BORRELLI, G. M.; TRONO, D. Recombinant lipases and phospholipases and their use as biocatalysts for industrial applications. Int J Mol Sci, vol. 16, n. 9, p. 2077420840, 2015.

[18] JENSEN, R. G. Characteristics of the lipase from the mold, Geotrichum candidum: A review. Lipids, vol. 9, n. 3, p. 149-157, 1974. 
Revista Ciências Exatas e Naturais, Vol.20, nº.1, Jan/Jun, 2018

[19] CORTEZ, D. V.; CASTRO, H. F.; ANDRADE, G. S. Potential catalytic of myceliumbound lipase of filamentous fungi in biotransformation processes. Quím Nova, vol. 40, n. 1, p. 85-96, 2017.

[20] CHAUHAN, M.; YENNAMALLI, R. M.; GARLAPATI, V. K. Biochemical characterization and molecular modeling of a unique lipase from Staphylococcus arlettae JPBW1. Eng Life Sci, vol. 16, n. 8, p. 762-768, 2016.

[21] RAMOS, L. P.; DA SILVA, F. R.; MANGRICH, A. S.; CORDEIRO, C. S. Tecnologias de produção de biodiesel. Rev Virtual Quim, vol. 3, n. 5, p. 385-405, 2011.

[22] GHOSH, P. K.; SAXENA, R. K.; GUPTA, R.; YADAV. R. P.; DAVIDSON, W. S. Microbial lipases: production and applications. Sci prog, vol. 79, p. 119-157, 1996.

[23] SHARMA, S.; KANWAR, S. S. Organic solvent tolerant lipases and applications. Sci World J, vol. 2014, 2014.

[24] MAHAlE, P. K.; DESAI, S. V.; HOMBALIMATH, V. S.; ACHAPPA, S. Isolation, screening and characterization of lipase producing strain from oil contaminated soil of Hubballi, Karnataka. Int J Basic and Appl Biol, vol. 2, n. 4, p. 198-201, 2015.

[25] ANDUALEMA, B.; GESSESSE, A. Microbial lipases and their industrial applications: review. Biotechnology, vol. 11, n. 3, p. 100-118, 2012.

[26] RODRIgueS, C.; CASSINI, S. T.; ANTUnES, P. W.; KELlER, R. P.; GONÇALVES, R. F. Isolamento e seleção de fungos produtores de lipases com base na atividade lipásica e no potencial hidrolítico sobre óleo comestível de soja e escuma de caixa de gordura. Eng sanit ambient, vol. 21, n. 3, p. 507-518, 2016.

[27] TREICHEL, H.; OLIVEIRA, D.; MAZUTTI, M. A.; DI LUCCIO, M.; OLIVEIRA, J. V. A review on microbial lipase production. Food Bioprocess Tech, vol. 3, p. 182-196, 2010 .

[28] SALIHU, A.; ALAM, M. Z.; ABDULKARIM, M. I.; SALLEH, H. M. Lipase production: an insight in the utilization of renewable agricultural residues. Resour Conser Recy, vol. 58, p. 36-44, 2012.

[29] KUO, T. C.; SHAW, J. F.; LEE, G. C. Conversion of crude Jatropha curcas seed oil into biodiesel using liquid recombinant Candida rugosa lipase isozymes. Bioresour technol, vol. 192, p. 54-59, 2015.

[30] NORAINI, M. Y.;ONG, H. C.; BADRUL, M. J.; CHONG, W. T. A review on potential enzymatic reaction for biofuel production from algae. Renew Sust Energ Rev, vol. 39, p. 24-34, 2014.

[31] BUSSAMARA, R.; FUENTEFRIA, A. M.; OLIVEIRA, E. S.; BROETTO, L.; SIMCIKOVA, M.; VALENTE, P.; SCHRANK, A.; VAINSTEIN, M. H. Isolation of a lipasesecreting yeast for enzyme production in a pilot-plant scale batch fermentation. Bioresour Technol, vol. 101, p. 268-275, 2010.

[32] GUPTA, R.; KUMARI, A.; SYAL, P.; SINGH, Y. Molecular and functional diversity of yeast and fungal lipases: their role in biotechnology and cellular physiology. Prog lipid res, vol. 57, p. 40-54, 2015. 
[33] BORA, L.; GOHAIN, D.; DAS. Recent advances in production and biotechnological applications of thermostable and alkaline bacterial lipases. J Chem Technol Biotechnol, vol. 88, n. 11, p. 1959-1970, 2013.

[34] RAMnATH, L.; SITHOLE, B.; GOVINDEN, R. Classification of lipolytic enzymes and their biotechnological applications in the pulping industry. Can J Microbiol, n. ja, 2016 .

[35] CIAFARDINI, G.; ZULLO, B. A.; IRIDE, A. Lipase production by yeasts from extra virgin olive oil. Food Microbiol, vol. 23, p. 60-67, 2006.

[36] FARINAS, C. S. Developments in solid-state fermentation for the production of biomass degrading enzymes for the bioenergy sector. Renew Sust Energ Rev, vol. 52, p. 179-188, 2015.

[37] SINGHANIA, R. R.; PATEL, A. K.; THOMAS, L.; PANDEY, A. Solid State Fermentation. Industrial Biotechnology: Products and Processes, p. 187-204, 2016.

[38] CONTESINI, F. J.; CALZADO, F.; MADEIRA, J. V.; RUBIO, M. V.; ZUBIETA, M. P.; DE MELO, R. R. Biotechnological and industrial application. Reference series in phytochemistry: Fungal metabolites, p. 1-28, 2016.

[39] SOCCOL, C. R.; DA COSTA, E. S. F.; LETTI, L. A. J.; KARP, S. G.; WOICIECHOWSKI, A. L.; DE SOUZA VANDENBERGHE, L. P. Recent developments and innovations in solid state fermentation. Biotechnology Research and Innovation, 2017.

[40] Messias, J. M.; COSTA, B. Z.; LIMA, V. M. G.; GIESE, E. C.; DEKKER, R. F. H.; BARBOSA, A. M. Lipases microbianas: produção propriedades e aplicações biotecnológicas. Semina: Ciências Exatas e Tecnológicas, vol. 32, n. 2, p. 213-234, 2011.

[41] SINGHANIA, R. R.; PATEL, A. K.; SOCCOL, C. R.; PANDEY, A. Recent advances in solid-state fermentation. Biochem Eng J, vol. 44, p. 13-18, 2009.

[42] KIRAN, E. U.; TRZCINSKI, A. P.; NG, W. J.; LIU, Y. Enzyme Production from Food Wastes Using a Biorefinery Concept. Waste Biomass Valorization, vol. 5, p. 903-917, 2014.

[43] COUTO, S. R.; SANROMAN, M. A. Application of solid-state fermentation to food industry- A review. J Food Eng, vol. 76, p. 291-302, 2006.

[44] WANG, D.; XU, Y.; SHAN, T. Effects of oils and oil-related substrates on the synthetic activity of membrane-bound lipase from Rhizopus chinensis and optimization of the lipase fermentation media. Biochem Eng J, vol. 41, p. 30-37, 2008.

[45] DE MORAIS, W. G.; KAMIMURA, E. S.; RIBEIRO, E. J.; PESSELA, B. C.; CARDOSO, V. L.; DE RESENDE, M. M. Optimization of the production and characterization of lipase from Candida rugosa and Geotrichum candidum in soybean molasses by submerged fermentation. Protein Expr Purif, vol. 123, p. 26-34, 2016.

[46] THOMAS, L.; LARROCHE, C.; PANDEY, A. Current developments in solid-state fermentation. Biochem Eng J, vol. 81, p. 146-161, 2013. 
Revista Ciências Exatas e Naturais, Vol.20, nº.1, Jan/Jun, 2018

[47] MAIA, M. M. D.; HEASLEY, A.; MORAIS, M. M. C.; MELO, E. H. M.; MORAIS JR., M. A.; LEDINGHAM, W. M.; FILHO, J. L. L. Effect of culture conditions on lipase production by Fusarium solani in batch fermentation. Bioresour Technol, vol. 76, p. 23-27, 2001.

[48] FREIRE, D. M. G.; GOMES, P. M.; BOM, E. P. S.; SANT'ANNA, G. L. JR. Lipase production by a new promissing strain Penicillium restrictum. Rev Microbiol, vol. 28, p. 6-12, 1997.

[49] HABA, E.; BRESCO, O.; FERRER, C.; MARQUES, A.; BUSQUETS, M.; MANRESA, A. Isolation of lipase-screening bacteria by deploying used frying oil as selective substrate. Enzyme microb technol, vol. 26, p. 40-44, 2000.

[50] TAN, T.; ZHANG, M. X.; ZHANG, J. Optimization of culture conditions and properties of lipase from Penicillium camembertii Thom PG-3. Process Biochem, vol. 39, p. 1495-1502, 2004.

[51] BANCERZ, R.; GINALSKA, G.; FIEDUREK, J.; GROMADA, A. A novel thermostable lipase from Basidiomycete Bjerkandera adusta R59: Characterization and esterification studies. J Ind Microbiol Biot, vol. 34, p. 553-560, 2005.

[52] MAKHSUMKHANOV, A. A.; YAKUBOV, I. T.; DAVRANOV, K. Conditions for cultivation of the fungus Penicillium melinii UZLM-4 and its biosynthesis of lipases. Appl Biochem Microbiol, vol. 39, n. 1, p. 40-43, 2003.

[53] TOMmaSO, G.; DE MORAES, B. S.; MACEDO, G.; SILVA, G. S.; KAMIMURA, E. S. Production of lipase from Candida rugosa using cheese whey through experimental design and surface response methodology. Food Bioprocess Technol, vol. 4, p. 14731481, 2011.

[54] MALISZEWSKA, I.; MASTALERZ, P. Production and some properties of lipase from Penicillium citrinum. Enzyme Microb Technol, vol. 14, n. 3, p. 190-193, 1992.

[55] MirandA, O. A.; SAlgueiro, A. A.; PIMENTEL, M. C. B.; LIMA FILHO, J. L.; MELO, E. H. M.; DUR'AN, N. Lipase production by a Brazilian strain of Penicillium citrinum using an industrial residue. Bioresour Technol, vol. 69, p. 145-147, 1999.

[56] SHU, C. H.; XU, C. J.; LIN, G. C. Purification and partial characterization of a lipase from Antrodia cinnamomea. Process Biochem, vol. 41, p. 734-738, 2006.

[57] CHAHINIAN, H.; VANOT, G.; IBRIK, A.; RUGANI, N.; SARDA, L.; COMEAU, L. C. Production of extracellular lipases by Penicillium cyclopium. Biosci Biotechnol Biochem, vol. 64, p. 215-222, 2006.

[58] AMIN, M.; BHATTI, H. N.; ZUBER, M.; BHATTI, I. A.; ASGHER, M. Potential use of agricultural wastes for the production of lipase by Aspergillus melleus under solid state fermentation. J Anim Plant Scis, vol. 24, n. 5, p. 1430-1437, 2014.

[59] BHATTI, H. N.; AMIN, F. Kinetic and Hydrolytic Characterization of Newly Isolated Alkaline Lipase from Ganoderma lucidum using Canola oil Cake as Substrate J Chem Soc Pak, vol. 35, n. 3, p. 585-592, 2013. 
[60] DAmaso, M. C. T.; PASSIANOTO, M. A.; FREITAS, S. C.; FREIRE, D. M. G.; LAGO, R. C. A.; COURI, S. Utilization of agroindustrial residues for lipase production by solid-state fermentatios. Braz J Microbiol, vol. 39, p. 676-681, 2008.

[61] Fleuri, L. F.; NOVElli, P. K.; Delgado, C. H. O.; PIVETTA, M. R.; PEREIRA, M. S.; ARCURI, M. L.; CAPOVILLE, B. L. Biochemical characterisation and application of lipases produced by Aspergillus sp. on solid-state fermentation using three substrates. Int J Food Sci Technol, vol. 49, p. 2585-2591, 2014.

[62] KHAYATI, G.; KIYANI, F. A statistical approach for optimization of lipase production by using rice straw: analysis of different inducers and nitrogen sources effect. Minerva Biotecnol, vol. 24, n. 3, p. 83-89, 2012.

[63] MOFTAH, O. A. S.; GRBAVČIĆ, S. Ž.; MOFTAH, W. A. S.; LUKOVIĆ, N. D.; PRODANOVIĆ, O. L.; JAKOVETIĆ, S. M.; KNEŽEVIĆ-JUGOVIĆ, Z. D. Lipase production by Yarrowia lipolytica using olive oil processing wastes as substrates. J Serb Chem Soc, vol. 78, p. 781-794, 2013.

[64] NIAZ, M.; IFTIKHAR, T.; AKRAM, F.; NIAZ, M. Protocol optimization for extracellular lipase production by trichophyton spp. (MBL 23) under solid state fermentation. Pak J Bot, vol. 45, p. 1417-1421, 2013.

[65] OLIVEIRA, B. H.; CORADI, G. V.; ATTILI-ANGELIS, D.; SCAURI, C.; LUQUES, A. H. P. G.; BARBOSA, A. M.; DEKKER, R. F. H.; NETO, P. O.; LIMA, V. M. G. Comparison of lipase production on crambe oil and meal by Fusarium sp. (Gibberella fujikuroi complex). Eur J Lipid Sci Technol, vol. 115, p. 1413-1425, 2013.

[66] RAJENDRAN, A.; THANGAVELU, V. Utilizing Agricultural Wastes as Substrates for Lipase Production by Candida rugosa NCIM 3462 in SolidState Fermentation: Response Surface Optimization of Fermentation Parameter. Waste Biomass Valor, vol. 4, p. 347-357, 2013.

[67] SILVA, M. F.; FREIRE, D. M. G.; DE CASTRO, A. M.; LUCCIO, M. D.; MAZUTTI, M. A.; OLIVEIRA, J. V.; TREICHEL, H.; OLIVEIRA, D. Production of multifunctional lipases by Penicillium verrucosum and Penicillium brevicompactum under solid state fermentation of babassu cake and castor meal. Bioproces. Biosyst Eng, vol. 34, p. $145-152,2011$.

[68] VenKatesagowdA, B.; PONUGUPATy, E.; BARBOSA, A. M.; DEKKER, R. F. H. Solid state fermentation of coconut kernel-cake as substrate for the production of lipases by the coconut kernel-associated fungus Lasiodiplodia theobromae VBE-1. Ann Microbiol, vol. 65, n. 1, p. 129-142, 2015.

[69] OLIVEIRA, B. H.; CORADI, G. V.; ATTILI ANGELIS, D.; SCAURI, C.; LUQUES, A. H. P.; BARBOSA, A. M.; DEKKER, R. F. H.; NETO, P. O.; LIMA, V. M. G. Comparison of lipase production on crambe oil and meal by Fusarium sp.(Gibberella fujikuroi complex). Eur J Lipid Sci Tech, vol. 115, n. 12, p. 1413-1425, 2013.

[70] SARKAR, D.; LAHA, S. Optimization of extracellular lipase enzyme production from Aspergillus niger by submerged and solid state fermentation process. Int J Pharma Bio Sci, vol. 4, n. 4, p. 978-985, 2013. 
Revista Ciências Exatas e Naturais, Vol.20 , nº.1, Jan/Jun, 2018

[71] RAJAN, A.; NAIR, A. J. A comparative study on alkaline lipase production by a newly isolated Aspergillus fumigatus MTCC 9657 in submerged and solid-state fermentation using economically and industrially feasible substrate. Turk J Biol, vol. 35, n. 5, p. 569-574, 2011.

[72] ROBERT, J. M.; LATTARI, F. S.; MACHADO, A. C.; DE CASTRO, A. M.; ALMEIDA, R. V.; TORRES, F. A. G.; VALERO, F.; FREIRE, D. M. G. Production of recombinant lipase B from Candida antarctica in Pichia pastoris under control of the promoter PGK using crude glycerol from biodiesel production as carbon source. Biochem Eng J, vol. 118, p. 123-131, 2017.

[73] JALlOUli, R.; PARSIEGlA, G.; CARRIÈRE, F.; GARGOURI, Y.; BEZZINE, S. Efficient heterologous expression of Fusarium solani lipase, FSL2, in Pichia pastoris, functional characterization of the recombinant enzyme and molecular modeling. Int Journal Biol Macromolec, vol. 94, p. 61-71, 2017.

[74] MENONCIN, S.; DOMINGUES, N. M.; FREIRE, D. M. G.; TONIAZZO, G.; CANSIAN, R. L.; OLIVEIRA, J. V.; DI LUCCIO, M.; OLIVEIRA, D.; TREICHEL, H. Study of the Extraction, Concentration, and Partial Characterization of Lipases Obtained from Penicillium verrucosum using Solid State Fermentation of Soybean Bran. Food Bioprocess Technol, vol. 3, p. 537-544, 2010.

[75] PALEKAR , A. A.; VASUDEVAN, P. T.; YAN, S. Purification of lipase: a Review. Biocatal Biotransform, vol. 18, p. 177-200, 2000.

[76] KUMAREVEL, T. S.; GOPINATH S. C. B.; HILDA, A.; GAUTHAM, N.; PONNUSAMY, M. N. Purification of lipase from Cunninghamella verticillata by stepwise precipitation and optimized conditions for crystallization. World J Microbiol Biotechnol, vol. 21, p. 23-26, 2005.

[77] SAXENA, R. K.; SHEORAN, A.; GIRI, B.; DAVIDSON, W. S. Purification strategies for microbial lipases. J Microbiol Methods, vol. 52, p. 1-18, 2003.

[78] KUMAR, R.; SHARMA, A.; KUMAR, A.; ;SINGH, D. Lipase from Bacillus pumilus RK31: production, purification and some properties. World Appl Sci J, vol. 16, n. 7, p. $940-948,2012$.

[79] LIANGhUA, T.; LIMING, X.; MIN, S.; HUAYING, G. Purification and application of a lipase from Penicillium expansum PED-03. Appl Biochem biotechnol, vol. 142, n. 2, p. 194-199, 2007.

[80] CAO, Y.; ZHUANG, Y.; YAO, C.; WU, B.; ;HE, B. Purification and characterization of an organic solvent-stable lipase from Pseudomonas stutzeri LC2-8 and its application for efficient resolution of (R, S)-1-phenylethanol. Biochem Eng J, vol. 64, p. 55-60, 2012 .

[81] GAIKAIWARI, R. P.; WAGH, S. A.; KULKARNI, B. D. Efficient lipase purification using reverse micellar extraction. Bioresour Technol, vol. 108, p. 224-230, 2012.

[82] HIOL, A.; JONZO, M. D.; RUGANI, N.; DRUET, D.; SARDA, L.; COMEAU, L. C. Purification and characterization of an extracellular lipase from a thermophilic Rhizopus oryzae strain isolated from palm fruit. Enzyme microb technol, vol. 26, n. 5, p. 421-430, 2000. 
[83] SOUZA, R. L.; LIMA, R. A.; COUTINHO, J. A.; SOARES, C. M.; LIMA, Á. S. Aqueous two-phase systems based on cholinium salts and tetrahydrofuran and their use for lipase purification. Separation and Purification Technology, vol. 155, p. 118-126, 2015 .

[84] SAXENA, R. K.; SHEORAN, A.; GIRI, B.; DAVIDSON, W. S. Purification strategies for microbial lipases. J Microbiol Methods, vol. 52, p. 1-18, 2003.

[85] AIRES-BARROS, M. R.; TAIPA, M. A.; CABRAL, J. M. S. In: Wooley P, Petersen SB (eds) Lipases their structure, biochemistry and application. Cambridge, University Press, p. 243-270. 1994.

[86] PALEKAR , A. A.; VASUdEVAN, P. T.; YAN, S. Purification of lipase: a Review. Biocatal Biotransform, vol. 18, p. 177-200, 2000.

[87] KUMAREVEL, T. S.; GOPINATH S. C. B.; HILDA, A.; GAUTHAM, N.; PONNUSAMY, M. N. Purification of lipase from Cunninghamella verticillata by stepwise precipitation and optimized conditions for crystallization. World J Microbiol Biotechnol, vol. 21, p. 23-26, 2005.

[88] BORKAR, P. S.; BODADE, R. G.; RAO, S. R.; KHOBRAGADE, C. N. Purification and characterization of extracellular lipase from a new strain-Pseudomonas aeruginosa SRT9. Braz J Micobiol, vol. 40, p. 358-366, 2009.

[89] KOBLITZ, M. G. B.; PASTORE, G. M. Purificação parcial, por dois diferentes métodos cromatográficos, da lipase produzida por Rhizopus sp. Ciênc Tecnol Aliment, vol. 24, p. 287-292, 2004.

[90] GUPTA, R.; GUPTA, N.; RATHI, P. Bacterial lipases: An overview of production, purification and biochemical properties. Appl Microbiol Biotechnol, vol. 64, p. 763-781, 2004 .

[91] TAN, C. H.; SHOW, P. L.; OOI, C. W.; NG, E. P.; LAN, J. C. W.; LING, T. C. Novel lipase purification methods - a review of the latest developments. Biotechnol J, v. 10, n. 1, p. 31-44, 2015.

[92] SHIN, Y. O.; VERA, J. H. Solubilization limit of lysozyme into DODMAC reverse micelles. Biotechnol Bioeng, vol. 80, p. 537-543, 2002.

[93] ADLERCREUTZ, P. Immobilisation and application of lipases in organic media. Chem Soc Rev, vol. 42, p. 6406-6436, 2013.

[94] GARCIA-GALAN, C.; BERENGUER-MURCIA, A.; FERNANDEZ-LAFUENTE, R.; RODRIGUES, R. C. Potential of different enzyme immobilization strategies to improve enzyme performance. Adv Synth Catal, vol. 353, p. 2885-2904, 2011.

[95] CARVAlHO, N. B.; LIMA, A. S.; SOARES, C. M. F. Uso de sílicas modificadas para imobilização de lipases. Quim Nova, vol. 38, p. 399-409, 2015.

[96] HARTMANN, M.; KOSTROV, X. Immobilization of enzymes on porous silicas benefits and challenges. Chem Soc Rev, vol. 42, p. 6277-6290, 2013. 
Revista Ciências Exatas e Naturais, Vol.20 , nº.1, Jan/Jun, 2018

[97] MALCATA, F.; REYES, H. R.; GARCIA, H. S.; HILL, C. G. Immobilized lipase reactors for modification of fats and oils - a review. J Am Oil Chem Soc, vol. 67, p. 890-910, 1990.

[98] ANSARI, S. A.; HUSAIN, Q. Potential applications of enzymes immobilized on/in nano materials: A review. Biotechnol Adv, vol. 30, p. 512-523, 2012.

[99] DALLA-VECCHIA, R.; NASCIMENTO, M. G.; SOLDI, V. Aplicações sintéticas de lipases imobilizadas em polímeros. Quím Nova, vol. 27, p. 623-630, 2004.

[100] HWANG, E. T.; GU, M. B. Enzyme stabilization by nano/microsized hybrid materials. Eng Life Sci, vol. 1, p. 49-61, 2013. 